\title{
Eyelid and brow asymmetry in patients evaluated for upper lid blepharoplasty
}

Kristian I Macdonald ${ }^{1 *}$, Adrian I Mendez ${ }^{2}$, Robert D Hart ${ }^{3}$ and S Mark Taylor ${ }^{3}$

\begin{abstract}
Introduction: In evaluation for blepharoplasty, patients often desire improved cosmesis and/or correction of visual field deficits. However, patients are usually unaware of eyelid or brow asymmetry. Furthermore, the prevalence of eyelid and brow asymmetry is infrequently reported in the medical literature.
\end{abstract}

Purpose: To determine the prevalence of brow and eyelid asymmetry in patients evaluated for upper lid blepharoplasty.

Methods: One hundred consecutive patients evaluated for upper lid blepharoplasty were included in the study. Standard pre-operative photographs were taken of all patients using consistent background and photographic equipment. Two of the authors (KM \& AM) independently recorded the margin pupil (MPD), central eyebrow (CED), nasal eyebrow (NED) and temporal eyebrow (TED) distances. To test the inter-observer reliability, the senior author (SMT) recorded the same measurements for $10 \%$ of randomly selected patients. We calculated $95 \%$ confidence intervals to compare symmetry between the right and left sides.

Results: One hundred patients (94 female, mean age 57.7) were included in the study. The average MPD, CED, NED and TED distances were $0.55 \mathrm{~mm}$ (95\% Cl 0.45-0.65), $1.77 \mathrm{~mm}$ (95\% Cl 1.47-2.07), 1.34 mm (95\% Cl 1.14-1.54), and $1.78 \mathrm{~mm}(95 \% \mathrm{Cl} 1.50-2.06)$, respectively. Ninety-three percent of patients had at least one asymmetric measurement of greater than $1 \mathrm{~mm}$. Seventy-five percent of patients studied had at least one measurement greater than $2 \mathrm{~mm}$ while 37 percent had at least one greater than $3 \mathrm{~mm}$.

Conclusion: Brow and eyelid asymmetry is common in patients being evaluated for upper lid blepharoplasty. The facial plastic surgeon should identify and document facial asymmetry pre-operatively, and discuss it with prospective blepharoplasty patients. This will improve informed consent and patient expectations.

Keywords: Eyelid, Eyebrow, Symmetry, Asymmetry, Blepharoplasty, Informed consent, Patient evaluation

\section{Background}

In evaluation for blepharoplasty, patients often desire improved cosmesis and/or correction of visual field deficits. However, patients are usually unaware of eyelid or brow asymmetry [1-3]. This is interesting to note, given the importance of facial symmetry in defining beauty $[4,5]$.

Preoperatively, it is important to identify and inform the patient of the presence of eyelid and brow asymmetry $[1,6]$. This will allow for a comprehensive surgical plan, and will help ensure reasonable patient expectations.

\footnotetext{
* Correspondence: kristian.macdonald@gmail.com

'Department of Otolaryngology - Head \& Neck Surgery, University of

Ottawa, 1081 Carling Ave, Ottawa, ON K1Y 4G2, Canada

Full list of author information is available at the end of the article
}

Although there is no clear consensus on what degree of asymmetry is of clinical importance, some authors report that facial asymmetry as little as $1 \mathrm{~mm}$ is of significance and warrants attention [7-9].

The prevalence of eyelid and brow asymmetry is infrequently reported in the medical literature. Song et al. reported a $30 \%$ asymmetry of the palpebral fissure in a random population of 594 Koreans [8]. A study examining photos of models in popular magazines found that $10 \%$ had asymmetry of several measures of eyelid and brow height [9].

It is the senior author's (SMT) hypothesis that a significant proportion of patients presenting for evaluation for blepharoplasty have eyelid and/or brow asymmetry. This group is particularly interesting to study, as although they 


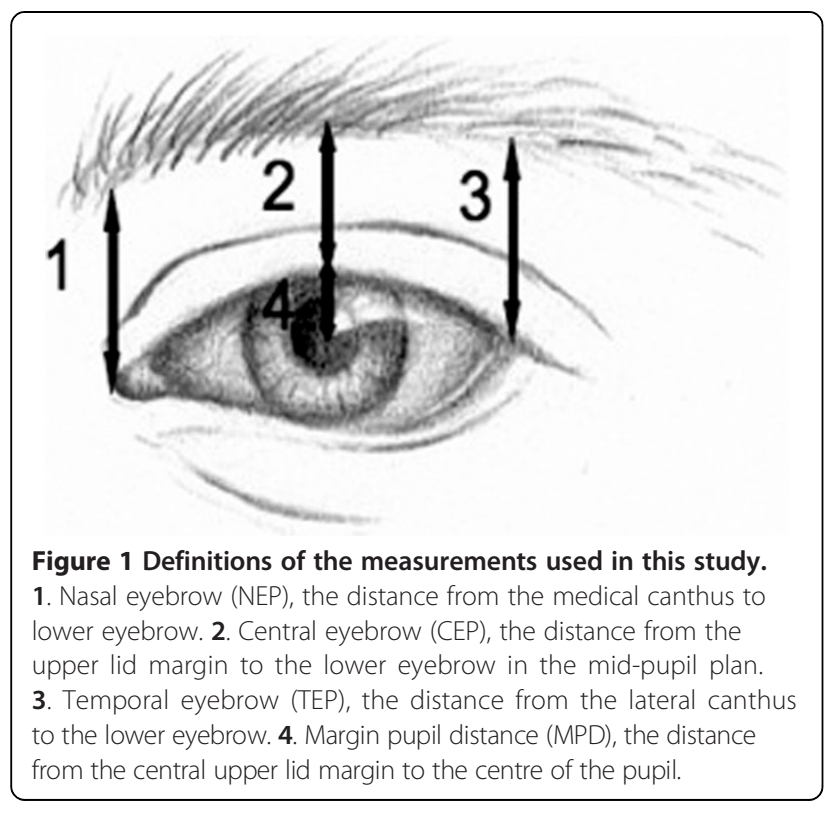

are inquiring about eyelid surgery, most are unaware of any existing asymmetry.

\section{Methods}

This retrospective chart review was approved by the local research ethics board at Dalhousie University in Halifax, NS, Canada. We included consecutive patients who were evaluated for upper lid blepharoplasty. Patients were excluded if they had a documented eyelid or brow asymmetry with a defined cause, including previous surgery and/or facial nerve palsy.

Preoperative pictures were taken in a standardized fashion with the same camera, at zero magnification, at the same distance from the patient. From these pictures, a senior (KM) and a junior Otolaryngology - Head \& Neck Surgery resident (AM) independently measured the four distances detailed in Figure 1 for each eye. These were the margin pupil (MPD), the central eyebrow (CED), the nasal eyebrow (NED), and the temporal eyebrow (TEP) distances.

For each measurement, the mean asymmetry with 95\% confidence interval was calculated. We also determined

Table 1 Number of patients with asymmetry with 3 different limits

\begin{tabular}{llll}
\hline Measurement & $\mathbf{2 1} \mathbf{~ m m}$ & $\mathbf{2} \mathbf{~ m m}$ & $\mathbf{2 3} \mathbf{~ m m}$ \\
\hline MPD & 11 & 3 & 1 \\
CED & 58 & 38 & 18 \\
NED & 50 & 25 & 10 \\
TED & 61 & 41 & 18 \\
$\geq \mathbf{1}$ measurement of asymmetry & 93 & 75 & 37
\end{tabular}

MPD = Margin pupil distance; CED = Central eye distance; NED = Nasal eye distance; TED = Temporal eye distance.

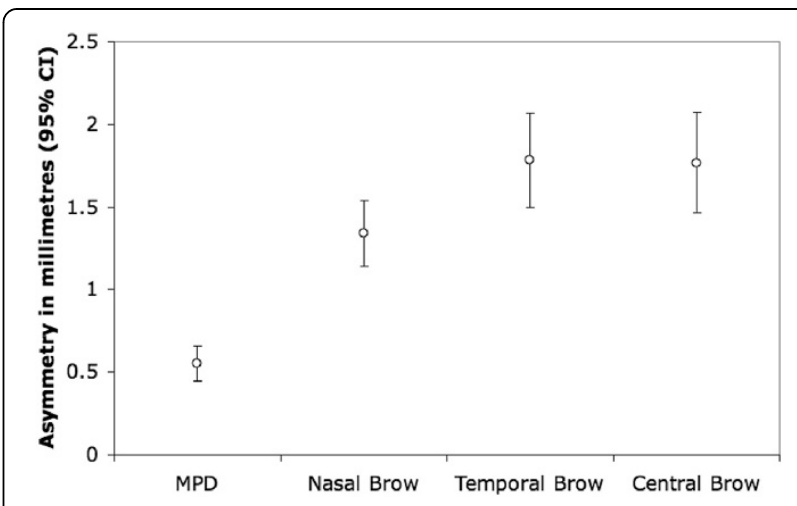

Figure 2 Average eyelid and brow asymmetries for 100 patients. MPD = Margin pupil distance.

the proportion of patients who had equal to or greater than 1, 2 and $3 \mathrm{~mm}$ asymmetry for each measurement. To test for inter-observer reliability, $10 \%$ of the patients were randomly selected for independent measurements by the senior author, a facial plastic surgeon (SMT). These measurements and asymmetries were compared to those of the other two authors.

\section{Results}

One hundred consecutive patients who presented for evaluation for upper lid blepharoplasty were included in the analysis. None of the patients were excluded. There were 97 Caucasians and 3 Asian patients in the study cohort. 94 patients were female, and 6 were male. The average age of the group was $57.7+/-10$ years.

The 10 sets of randomly selected patients measured by the senior author were compared to those of the first author. Although some of the actual measurements varied slightly, the asymmetries were within $0.1 \mathrm{~mm}$ for all 40 measurements.

The proportions of patients with $\geq 1,2$ and $3 \mathrm{~mm}$ of asymmetry are presented in Table 1 . In summary, $93 \%$ of patients had greater than or equal to $1 \mathrm{~mm}$ of asymmetry in at least one of four measurements, $75 \%$ had greater than or equal to $2 \mathrm{~mm}$, and $37 \%$ had greater than or equal to $3 \mathrm{~mm}$.

Figure 2 reports the average asymmetry, in millimeters, for each of the four measurements. The average MPD, NED, TED and CED were $0.55 \mathrm{~mm}$ (95\% CI 0.44-

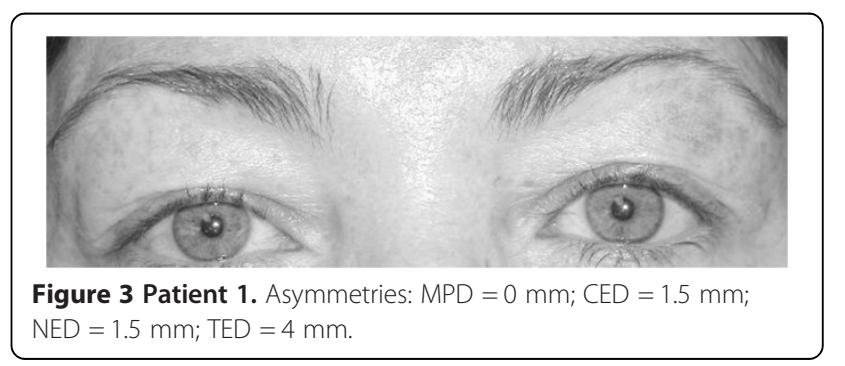




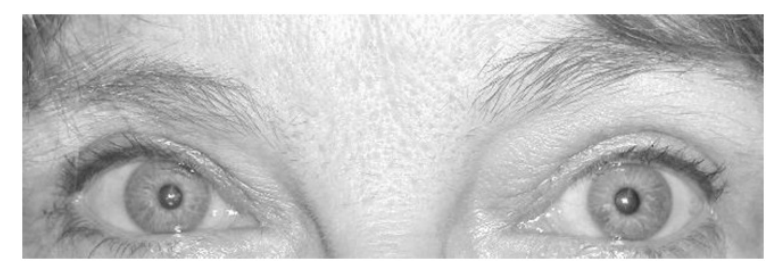

Figure 4 Patient 2. Asymmetries: $M P D=0 \mathrm{~mm} ; C E D=5.5 \mathrm{~mm}$; $\mathrm{NED}=6 \mathrm{~mm} ; \mathrm{TED}=3.5 \mathrm{~mm}$.

0.66), $1.34 \mathrm{~mm}$ (95\% CI 1.14-1.54), $1.78 \mathrm{~mm}$ (95\% CI 1.49-2.07), and $1.77 \mathrm{~mm}$ (95\% CI 1.46-2.07), respectively.

Two examples are presented in Figures 3 and 4. Both patients were females in their early 40 's who had requested a more youthful appearance of their upper eyelids. The first patient (Figure 3 ) had a $4 \mathrm{~mm}$ asymmetry in the temporal eye distance, with the right side higher than the left. The second patient (Figure 4) had a more obvious asymmetry, with a central eye distance asymmetry of $5.5 \mathrm{~mm}$. Neither patient noted their asymmetry as a complaint or reason for requesting surgery.

\section{Discussion}

Published literature on facial analysis has stressed the importance of preoperatively identifying facial asymmetry $[1-3,10]$. However, the actual prevalence of eyelid and brow asymmetry is rarely reported. Searches online in Medline with the terms "eyelid asymmetry", "brow asymmetry", "photo analysis and eyelids", and "facial asymmetry and aesthetics", yielded few relevant studies.

Ing et al. evaluated 102 models in popular magazine photographs [9]. They measured 14 ocular parameters, and identified a mean asymmetry of $0.2-2.4 \mathrm{~mm} .12$ of the models had an asymmetry of 2 standard deviations from the mean, concluding that a significant number of models had substantial facial asymmetry.

In another study, Song et al. sought to quantify asymmetry of palpebral fissure height in normal Koreans [8]. They recruited 594 patients from the general population, and determined the prevalence of asymmetry greater than $1 \mathrm{~mm}$. They found that $24.2 \%$ of males and $26.5 \%$ of females had such an asymmetry. The authors called for similar studies in Caucasians.

Our patient population is particularly interesting, as they are mostly female Caucasians (94\%) who sought surgical correction of the upper eyelid. Although they had paid particular attention to their eyes, they were not aware of, or at least did not make note of any asymmetry during their clinic visit. We could not identify other studies in which eyelid or brow asymmetry was assessed in patients presenting for blepharoplasty.

Despite this, the vast majority of our patients (93\%) had, in at least one of the four measurements, asymmetry greater than or equal to $1 \mathrm{~mm}$. Using more stringent criteria, three quarters of patients had an asymmetry greater than or equal to $2 \mathrm{~mm}$, in at least one of the measurements.

Awareness of the prevalence of asymmetry is important for the facial plastic surgeon. It will enhance the preoperative evaluation, help optimize the surgical plan and improve patient expectations and satisfaction. Once their other concerns are addressed, patients who were not aware of asymmetries preoperatively may be more likely to take notice postoperatively, and could conclude that they are iatrogenic in etiology. It is therefore critical that the facial plastic surgeon identifies potential asymmetry preoperatively and educates the patient appropriately.

\section{Conclusion}

The vast majority of patients presenting for evaluation for upper lid blepharoplasty had eyelid or brow asymmetry greater than or equal to $1 \mathrm{~mm}$. Temporal and central eyebrow distances showed the greatest asymmetry. This knowledge is critical for the facial plastic surgeon, and any potential asymmetry should be identified and discussed preoperatively with blepharoplasty patients.

\section{Consent}

Written informed consent was obtained from the patient for the publication of this report and any accompanying images.

\section{Competing interests}

The authors declare that they have no competing interests.

\section{Authors' contributions}

SMT conceived and designed the study, aided in data acquisition, and critically revised the manuscript. KM obtained ethics approval, performed the data analysis, and wrote the initial manuscript draft, including tables and figures. AM participated in data acquisition, and in revising the manuscript. $\mathrm{RH}$ participated in revising the manuscript. All authors read and approved the final manuscript.

\section{Author details}

${ }^{1}$ Department of Otolaryngology - Head \& Neck Surgery, University of Ottawa, 1081 Carling Ave, Ottawa, ON K1Y 4G2, Canada. ${ }^{2}$ Division of Otolaryngology - Head \& Neck Surgery, University of Alberta, Edmonton, AB, Canada. ${ }^{3}$ Division of Otolaryngology - Head \& Neck Surgery, Dalhousie University, Halifax, NS, Canada.

Received: 29 May 2014 Accepted: 24 August 2014

Published online: 02 October 2014

\section{References}

1. Pastorek N: Blepharoplasty. In Head \& Neck Surgery - Otolaryngology. 4th edition. Edited by Bailey BJ, Johnson JT. Philadelphia: Lippincott Williams \& Wilkins; 2006:2611-2626.

2. Kowner R: Facial asymmetry and attractiveness judgment in developmental perspective. J Exp Psychol Hum Percept Perform 1996, 22(3):662-675.

3. Tiryaki T, Ciloglu NS: Eyebrow asymmetry: definition and symmetrical correction using botulinum toxin A. Aesthet Surg J 2007, 27:513-517.

4. Mealey L, Bridgstock R, Townsend GC: Symmetry and perceived facial attractiveness: a monozygotic co-twin comparison. J Pers Soc Psychol 1999, 76(1):151-158.

5. Grammer K, Thornhill R: Human facial attractiveness and sexual selection: the role of symmetry and averageness. J Comp Psychol 1994, 108(3):233-242. 
6. Calhoun KH, Stambaugh KI: Facial analysis and preoperative evaluation. In Head \& Neck Surgery - Otolaryngology. 4th edition. Edited by Bailey BJ, Johnson JT. Philadelphia: Lippincott Williams \& Wilkins; 2006:2481-2498.

7. Lam BL, Lam S, Walls RC: Prevalence of palpebral fissure asymmetry in white persons. Am J Ophthalmol 1995, 120(4):518-522.

8. Song WC, Kim SJ, Kim SH, Hu KS, Kim HJ, Koh KS: Asymmetry of the palpebral fissure and upper eyelid crease in Koreans. J Plast Reconstr Aesthet Surg 2007, 60:251-255.

9. Ing E, Safarpour A, Ing T, Ing S: Ocular adnexal asymmetry in models: a magazine photograph analysis. Can J Ophthalmol 2006, 41:175-182.

10. Hochman H, Beas RA: Scar camouflage. In Head \& Neck Surgeny - Otolanyngology. 4th edition. Edited by Bailey BJ, Johnson JT. Philadelphia: Lippincott Williams \& Wilkins; 2006:2411-2420.

doi:10.1186/s40463-014-0036-4

Cite this article as: Macdonald et al: Eyelid and brow asymmetry in patients evaluated for upper lid blepharoplasty. Journal of Otolaryngology Head and Neck Surgery 2014 43:36.

\section{Submit your next manuscript to BioMed Central and take full advantage of:}

- Convenient online submission

- Thorough peer review

- No space constraints or color figure charges

- Immediate publication on acceptance

- Inclusion in PubMed, CAS, Scopus and Google Scholar

- Research which is freely available for redistribution 